\title{
Potential relationship between genotype and clinical outcome in propionic acidaemia patients
}

\author{
C Pérez-Cerdá ${ }^{1}, \mathrm{~B}$ Merinero ${ }^{1}, \mathrm{P}$ Rodríguez-Pombo ${ }^{1}, \mathrm{~B}$ Pérez ${ }^{1}, \mathrm{LR}^{\mathrm{Desviat}}{ }^{1}, \mathrm{~S} \mathrm{Muro}^{1}$, \\ E Richard ${ }^{1}$, MJ García ${ }^{1}$, J Gangoiti ${ }^{1}$, P Ruiz Sala ${ }^{1}$, P Sanz ${ }^{1}$, P Briones ${ }^{2}$, A Ribes ${ }^{2}$, \\ M Martínez-Pardo ${ }^{3}$, J Campistol ${ }^{4}$, M Pérez $^{5}$, R Lama $^{6}, \mathrm{ML}$ Murga ${ }^{7}$, T Lema-Garrett ${ }^{8}$, \\ A Verdú ${ }^{9}$ and $M$ Ugarte $^{1}$
}

\footnotetext{
${ }^{1}$ Centro de Diagnóstico de Enfermedades Moleculares, Centro de Biología Molecular Severo Ochoa, CSIC-UAM, Madrid; ${ }^{2}$ Instituto de Bioquímica Clínica, Corporación Sanitaria y CSIC, Barcelona; ${ }^{3}$ Centro E Ramón y Cajal, Madrid; ${ }^{4} \mathrm{H}$ ospital San Juan de Dios, Barcelona; ${ }^{5} \mathrm{Hospital}$ Virgen del Rocío, Sevilla; ${ }^{6} \mathrm{Hospital}$ La Paz; ${ }^{7} \mathrm{Hospital}$ Príncipe de Asturias, Alcalá de Henares, Madrid; ${ }^{8} \mathrm{H}$ ospital Ntra Sra de Sonsoles, Avila; ${ }^{9}$ Hospital Virgen de la Salud, Toledo, Spain
}

\begin{abstract}
Propionic acidaemia (PA) is an autosomal recessive disorder caused by mutations in either of the PCCA or PCCB genes which encode the $\alpha$ and $\beta$ subunits, respectively, of the mitochondrial enzyme propionyl-CoA carboxylase (PCC). In this work we have examined the biochemical findings and clinical outcome of 37 Spanish PA patients in relation to the mutations found in both PCCA and PCCB genes. We have detected 27 early-onset and 10 late-onset cases, showing remarkably similar biochemical features without relation to either the age of onset of the disease or the defective gene they have. Twenty-one of the patients have so far survived and three of them, now adolescents, present normal development. Different biochemical procedures allowed us to identify the defective gene in 9 PCCA deficient and 28 PCCB deficient patients. Nine putative disease-causing mutations accounting for $77.7 \%$ of mutant alleles were identified among PCCA deficient patients, each one carrying a unique genotypic combination. Of PCCB mutant alleles $98 \%$ were characterised. Four common mutations (ins/ del, E168K, 1170insT and A497V) were found in 38/52 mutant chromosomes investigated, whereas the remainder of the alleles harbour 12 other different mutations. By examining the mutations identified both in PCCA and PCCB genes and the clinical evolution of patients, we have found a good correlation between certain mutations which can be considered as null with a severe phenotype, while certain missense mutations tend to be related to the late and mild forms of the disease. Expression studies, particularly of the missense mutations identified are necessary but other genetic and environmental factors probably contribute to the phenotypic variability observed in PA.
\end{abstract}

European Journal of Human Genetics (2000) 8, 187-194.

Keywords: propionic acidaemia; mutation analysis; phenotype/genotype correlation

\section{Introduction}

Propionic acidaemia (MIM 232000, MIM 232050) is caused by deficiency of the mitochondrial biotin-dependent enzyme propionyl-CoA carboxylase (PCC; EC 6.4.1.3) that catalyses

Correspondence: Professor M Ugarte, Centro de Biología Molecular 'Severo Ochoa', Universidad Autónoma de Madrid, Cantoblanco, 28049 Madrid, Spain. Tel: +34917347011; Fax: +34917347797;

E-mail: mugarte@cbm.uam.es

Received 15 July 1999; revised 10 October 1999; accepted 15 October 1999 the carboxylation of propionyl-CoA to D-methylmalonyCoA. ${ }^{1}$ In most affected patients the disease presents as a lifethreatening ketoacidosis during the neonatal period and is associated with mental retardation and early death; in addition, some patients show a chronic late-onset form with milder symptoms and long survival rate. PCC is probably a dodecamer enzyme composed of $\alpha$ and $\beta$ subunits ( $\alpha 6 \beta 6$ ), with the $\alpha$ subunit containing the biotin prosthetic group. ${ }^{2}$ PA results from mutations in either the PCCA or PCCB genes that encode for the $\alpha$ and $\beta$ PCC subunits, respectively, ${ }^{3}$ 
defining two main intergenic complementation groups pccA and $\mathrm{pccBC}$, the latter including two subgroups pccB and pccC. ${ }^{4}$ The PCCA gene is located on chromosome $13 q 32^{5}$ and the PCCB gene on chromosome 3q13.3-q22. .,6 $^{\text {. }}$

Prior to mutation analysis, identification of the responsible gene can be performed by complementation studies, by analysis of steady-state levels of PCC proteins, or by measurement of PCC activity in parents, as most parents of PCCBdeficient patients show normal levels of PCC activity rather than the 50\% level expected of heterozygotes. ${ }^{7}$ To date, 53PA mutations have been reported on both PCCA and PCCB genes, as recently reviewed. ${ }^{8} A$ great genetic heterogeneity is observed in the PCCA gene detecting no prevalent mutation in the patients investigated. However, a limited number of mutations in the PCCB gene accounts for most of the alleles investigated in both Caucasian and Oriental populations. Several reports compilating clinical and biochemical data have been published, ${ }^{9-12}$ but the relationship between phenotype and genotype has not yet been examined.

In this work, we present the biochemical picture and clinical features of 37 Spanish PA patients in relation to the mutations found in the PCCA and PCCB genes, exploring a potential phenotype-genotype correlation.

\section{Material and methods \\ Subjects}

Thirty-seven Spanish PA patients from 35 unrelated families were included in this study. Table 1 lists information about family history and survival of patients. Twenty-seven patients were grouped in early-onset form when symptoms appeared within the first 3 weeks of life and 10 of them in late-onset form presenting after two months of life. Two patients diagnosed at birth (ALT and DVA) were included in the early-onset group due to a previous neonatally affected sib. Most early-onset patients exhibited clinical signs of the intoxication-type disease with vomiting, somnolence and/or coma, hypotonia and abnormal movements as myoclonic jerks and convulsions in some cases. The clinical manifesta-

Table 1 Family history and survival of 37 Spanish propionic acidaemia patients

\begin{tabular}{llll}
\hline & $\begin{array}{l}\text { Early onset } \\
\text { (newborn-20d) }\end{array}$ & $\begin{array}{l}\text { Late onset } \\
(2 \mathrm{~m}-5.5 \mathrm{y})\end{array}$ & $\begin{array}{l}\text { \% of total } \\
\text { patients }\end{array}$ \\
\hline Number of patients & $27(73 \%)$ & $10(27 \%)$ & \\
Male/female & $9 / 18$ & $6 / 4$ & $40.5 / 59.5$ \\
Age at diagnosis & $26.9 \mathrm{~d}$ & $23.5 \mathrm{~m}$ & \\
& $(1 \mathrm{~d}-5 \mathrm{~m})$ & $(6 \mathrm{~m}-6 \mathrm{y})$ & \\
Consanguinity of parents & 4 & 1 & 13 \\
Unexplained family deaths & 5 & 2 & 19 \\
Affected siblings & 2 & 0 & 5 \\
Number of survivors & 13 & 8 & 57 \\
Present age of survivors & $6.6 \mathrm{y}$ & $12.6 \mathrm{y}$ & \\
& $(15 \mathrm{~m}-15.5 \mathrm{y})$ & $(2.5 \mathrm{y}-25 \mathrm{y})$ & \\
Median survival age of & $16.7 \mathrm{~m}$ & $16 \mathrm{~m} ; 5.5 \mathrm{y}$ & \\
deceased & $(15 \mathrm{~d}-6.5 \mathrm{y})$ & \multicolumn{3}{l}{} & \\
\hline
\end{tabular}

d: days; m: months; y: years; ranges are in parentheses. tions in the 10late-onset patients were more insidious and usually related to infections. When diagnosed, most patients had a remarkably similar biochemical phenotype, showing metabolic ketoacidosis, hyperammonaemia, hyperglycinaemia, hypocarnitinaemia $(<11 \mu \mathrm{mol} / \mathrm{l})$ and the characteristic urinary organic acids pattern of PA. The most consistently organic acids found were methylcitric and 3-hydroxypropionic acids, 3-hydroxy-2-methylbutyric acid, tiglylglycine and propionylglycine. PCC deficiency was confirmed by direct assay of fibroblasts or lymphocytes. PCC activity was less than $5 \%$ of controls, except for one late onset case (OVE) who showed a clearly high residual activity of $11 \%$. Clinical and biochemical details of some of these patients have al ready been described. ${ }^{13-18}$

\section{Samples}

Lymphocytes were isolated from heparinized blood, and skin fibroblasts from patients, parents and controls were cultured by standard procedures. Whole blood and dried blood spots were also obtained as DNA source from controls, patients and families.

\section{Genetic classification of PA patients}

Carboxylase activities, ${ }^{19}{ }^{3} \mathrm{H}$-biotin labelling experiments ${ }^{3}$ and complementation studies ${ }^{20}$ were performed as described earlier.

\section{Molecular studies}

Genomic DNA and total RNA were isolated from cultured skin fibroblasts by standard methods. ${ }^{21,22}$ Detection of mutations in the PCCA gene were done by sequencing overlapping fragments of the complete PCCA coding sequence obtained by RT-PCR or of known exonic fragments as described. ${ }^{23}$ PCCB mutations were analysed by direct cycle sequencing of each of the 15 PCCB exons using described primers. ${ }^{20}$ Western blot analysis was performed according to standard

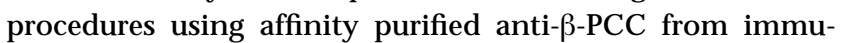
nised rabbits as primary antibody. ${ }^{24}$ Northern blot analysis was carried out according to standard procedure as described. ${ }^{23}$ The $\alpha$ and $\beta$ subunit cDNAs were both kindly provided by Dr D Leclerc and Professor RA Gravel.

\section{Results \\ Genetic classification of PA patients}

Of 37PA patients, 9 cases were identified as PCCA deficient and 28 ( 26 families) as PCCB deficient based on the following evidence.

Enzymatic findings in parents Carboxylase activities in fibroblasts or lymphocytes were measured in parents of 30 patients which resulted in identification of the defective gene in 27 of them. PCC activity in parents of 8PCCAdeficient patients showed intermediate values with a diminished PCC/MCC ratio. On the other hand, parents of 19 patients with mutations in the PCCB gene, showed normal 
PCC activity and PCC/MCC ratio as controls. The results of this study in parents' fibroblasts are summarised in Table2. In three families bearing mutations in the PCCB gene, we have found discrepant results. Both parents of MRA and PRG presented intermediate values measured in fibroblasts and the mother of NPU also showed an intermediate PCC activity value measured in lymphocytes (data not shown).

${ }^{3}$ H-Biotin labelling experiments With this procedure we have identified the defective gene in patients MRA, PRG and NPU whose parental PCC activities were uncertain and in seven patients with no parent sample available for enzymatic determination.

Three radioactive bands of $120 \mathrm{KDa}, 74 \mathrm{KDa}$ and $72 \mathrm{KDa}$ corresponding to the biotin containing polypeptides of $\mathrm{PC}$, $\alpha-M C C$ and $\alpha-P C C$, respectively, were detected after SDSPAGE and fluorography of a ${ }^{3} \mathrm{H}$-biotin labelled extract of normal cells (Figure1, laneC). Patients with defects in the PCCA gene showed no detectable band corresponding to the $\alpha$ chain of PCC (Figure 1, lanes 4, 6), except for case SAG who

Table 2 PCC activity in fibroblasts of parents of 20 patients with propionic acidaemia

\begin{tabular}{|c|c|c|c|}
\hline & $\begin{array}{l}\text { PCC }^{a} \text { activity } \\
\text { (pmol/min/ } \\
\text { mg protein) }\end{array}$ & $\begin{array}{l}\text { Ratio } \\
\text { PCC/MCC }\end{array}$ & $\begin{array}{l}\% \text { of mean } \\
\text { PCC }\end{array}$ \\
\hline $\begin{array}{l}\text { PCCA deficient group } \\
\text { Mean } \pm \mathrm{SD}(\mathrm{n}=12) \\
\text { (range) } \\
\text { PCCB deficient group }\end{array}$ & $\begin{array}{l}360 \pm 110 \\
(198-500)\end{array}$ & $\begin{array}{l}1.45 \pm 0.1 \\
(1.2-1.6)\end{array}$ & $41 \pm 13$ \\
\hline $\begin{array}{l}\text { Mean } \pm \text { SD }(n=24) \\
\text { (range) }\end{array}$ & $\begin{array}{l}992 \pm 300 \\
(500-2112)\end{array}$ & $\begin{array}{l}2.8 \pm 0.8 \\
(1.8-4.2)\end{array}$ & $103 \pm 44$ \\
\hline Parents MRA & $400 ; 310$ & & $44 ; 35$ \\
\hline $\begin{array}{l}\text { Parents PRG } \\
\text { Adult controls }\end{array}$ & $290 ; 240$ & $1.8 ; 2.0$ & $32 ; 27$ \\
\hline $\begin{array}{l}\text { Mean } \pm \text { SD }(n=9) \\
\text { (range) }\end{array}$ & $\begin{array}{l}893 \pm 300 \\
(598-1272)\end{array}$ & $\begin{array}{l}2.5 \pm 0.3 \\
(2.0-2.8)\end{array}$ & 100 \\
\hline
\end{tabular}

apropionyl-CoA carboxylase; ${ }^{b} \beta$-methylcrotonyl-CoA carboxylase. showed a faint band (Figure1, lane5), whereas patients bearing mutations in the PCCB gene had an $\alpha$-PCC radioactive band similar to controls (Figure 1, lanes 1,2 and 3).

Complementation tests Studies were performed in 15 patient cell lines. Cells were fused with tester pccA and pccBC cell lines followed by examination of the ${ }^{14} \mathrm{C}$-propionate incorporation rate (results not shown). The results obtained were in accordance with the previous assignment of patients to be PCCA or PCCB deficient patients performed by the above methods.

\section{Mutation analysis and clinical outcome}

A total of 9 and 16 different putative disease-causing mutations were detected in the PCCA and PCCB genes, respectively, accounting for $92.8 \%$ of all Spanish PA chromosomes.

The percentage of PCC activity, genotype and clinical features of nine PCCA deficient patients are given in Table3. Among the nine mutations identified in the PCCA gene no prevalent one was found. Two nonsense (R288X and S537X), three splicing (1771IVS-2del9, 1824IVS + 3del4 and 1824IVS + 3insCT) and four missense mutations (R52W, A113T, I139T and G606R) were identified. Data on all these mutations have been reported elsewhere. ${ }^{23,24}$ The I450V change, identified in two patients as homozygous, was present in $9 \%$ of controls, indicating a polymorphic variation. Until now, no change other than I450V polymorphism was found in patient DFH after sequencing the complete coding sequence. Four cases presented in the late-onset form of the disease and they are now alive, two of them (SAG and ESG) presenting a normal physical and mental development without dietary protein restrictions. Only one early-onset case (ANA) is alive but severely handicapped.

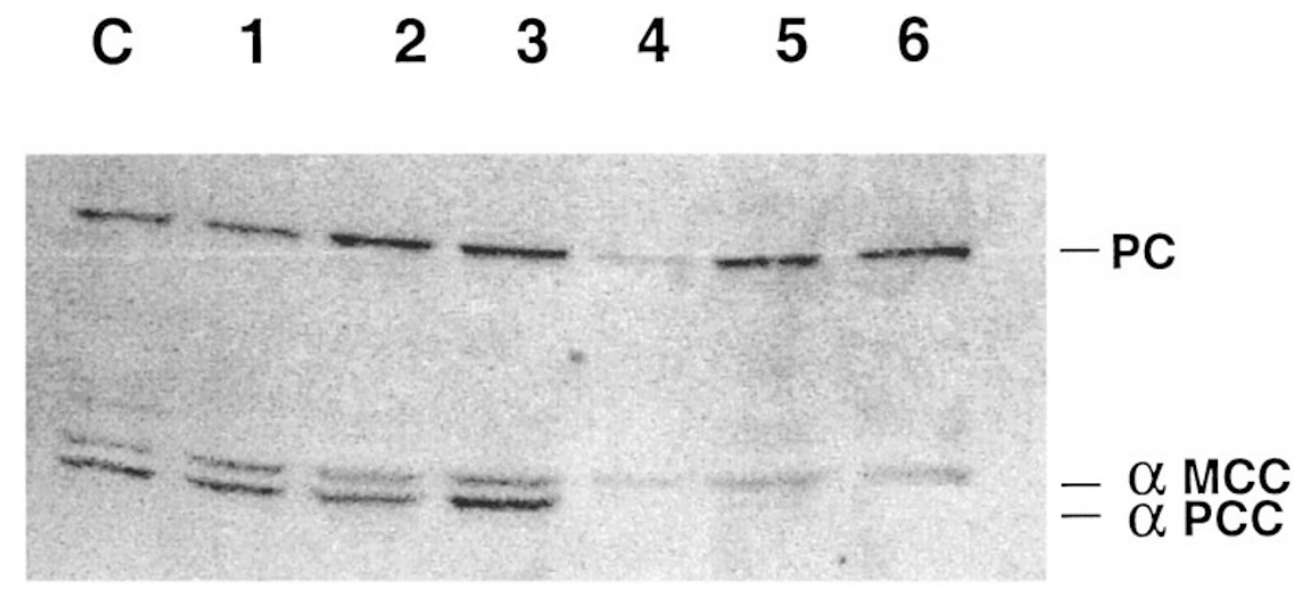

Figure 1 SDS-PAGE of ${ }^{3} \mathrm{H}$-biotin labeled extracts of normal and PCC-deficient fibroblasts detected by fluorography. Radioactive bands correspond to the biotin-containing polypeptides of PC $=$ pyruvate carboxylase; $\mathrm{MCC}=\beta$-methylcrotonyl CoA carboxylase and PCC = propionyl CoA carboxylase. C, control cell line; Lanes 1-3: PCCB-deficient patients MRA, PRG and NPU; lanes4-6: PCCA-deficient patients MPS, SAG and DFH respectively. 
Table 3 Genotype and clinical outcome of nine PCCA-deficient patients

\begin{tabular}{|c|c|c|c|c|}
\hline $\begin{array}{l}\text { Patient } \\
\left.\text { (Year of } d x^{a}\right)\end{array}$ & $\begin{array}{l}\text { Type of presentation } \\
\text { (Age onset/Age } \mathrm{dx} \text { ) }\end{array}$ & $\begin{array}{l}\% \mathrm{PCC}^{\mathrm{b}} \\
\text { activity }\end{array}$ & Genotype & Outcome \\
\hline MPS (1986) & Early (3d/7d) & 0 & R288X, R288X & $\begin{array}{l}\text { Died 6.5y when varicella. Psychomotor delay, convulsions } \\
\text { and feeding problems }\end{array}$ \\
\hline DFH (1988) & Early $(3 d / 8 d)$ & 0 & $1450 V^{P}, 1450 \mathrm{~V}$ & Died 1y \\
\hline ANA (1998) & Early $(20 d / 24 d)$ & 0 & S537X, S537X & $\begin{array}{l}\text { Alive 1.5y. Severe psychomotor delay and hypotonia. } \\
\text { Spastic tetraparesis. Weight p10th. LPD'. } C^{d}\end{array}$ \\
\hline JCS (1983) & Early $(2 d / 15 d)$ & 0 & G606R+1450V, G606R+1450V & Died 3y \\
\hline JMMO (1991) & Late $(3 \mathrm{~m} / 14 \mathrm{~m})$ & 4 & A113T, A113T & $\begin{array}{l}\text { Alive 9y. Mild psychomotor delay. Speech problems. } \\
\text { Normal MRI (3y). Psoriasis. Weight p50th and height } \\
\text { p90th. LPD.C }\end{array}$ \\
\hline SAG (1986) & Late $(15 \mathrm{~m} / 6 \mathrm{y})$ & 3.8 & R52W, 1771IVS-2del9 & $\begin{array}{l}\text { Alive 18.5y. Normal development. Weight p90th and } \\
\text { height p75th. NDPR f }\end{array}$ \\
\hline MSH (1979) & Late $(16 \mathrm{~m} / 17 \mathrm{~m})$ & 1.3 & $\begin{array}{l}\text { 1824IVS+3del4, } \\
\text { 1824IVS+3del4 }\end{array}$ & $\begin{array}{l}\text { Alive 21y. Microcephaly at birth. } \mathrm{IQ}^{9} \text { : } 59 \text {. Epilepsia crisis } \\
\text { 11-13y. Retarded puberal development. Weight and } \\
\text { height p90th. NDPR }\end{array}$ \\
\hline ESG (1984) & Late $(2 \mathrm{~m} / 7 \mathrm{~m})$ & 4 & I139T, ND & $\begin{array}{l}\text { Alive 15y. Normal development. Weight p50th and } \\
\text { height p75th. NDPR }\end{array}$ \\
\hline
\end{tabular}

adiagnosis; ${ }^{b}$ propionyl-CoA carboxylase; Ppolymorphism; 'low protein diet; ${ }^{\mathrm{d}}$ carnitine supplementation; ${ }^{\mathrm{e}}$ not detected; ${ }^{\mathrm{f}}$ no dietary protein restriction; 9intelligence quotient.

Details about nine (32.1\%) homozygous and 19 (67.8\%) heterozygous PCCB-deficient patients are listed in Tables 4 and 5 , respectively. It is noteworthy that PCCB homozygotes always present with early on set form. The mutation spectrum includes one insertion/deletion (1218del14ins12 or ins/del), two insertions (790-791insG and 1170insT), one nonsense mutation (W531X), two splice-site alterations (IVS1 + 3G $>C$ and IVS10-11del6) and ten missense mutations (R44P, S106R, G131R, E168K, G198D, R410W, M442T, A497V, R512C and L519P). Data on all these mutations have been reported elsewhere. ${ }^{20,25}$ The four mutations most frequently found were ins/del (29\%), E168K (19\%), 1170insT (17\%) and A497V (8\%). Over $50 \%$ of the patients are alive, $12 / 22$ earlyonset and 4/6late onset. All them show variable degrees of psychomotor delay and other systemic clinical complications except for three early-onset cases (PRG, JRC and PHG), who currently present good clinical development, and patient SVL who shows normal mental development at 13 years of age.

\section{Western blot analysis of $\boldsymbol{\beta}$-PCC subunit}

As previously reported, a total absence of immunoreactive $\beta$-PCC was detected in all patients carrying mutations in the PCCA gene, except for case SAG in whom traces of $\beta$-subunit were detectable $e^{23,24}$ and in the PCCB-deficient patients who were homozygous for ins/del or 1170insT mutations and in those patients who were compound heterozygotes for ins/del and R512C or 1170insT and L519P mutations. ${ }^{26}$ For the remaining PCCB deficient patients, an unstable $\beta$-PCC subunit reduced in quantity or partially degraded was observed. ${ }^{26}$

Table 4 Genotype and clinical outcome of nine homozygous PCCB-deficient patients

\begin{tabular}{|c|c|c|c|c|}
\hline $\begin{array}{l}\text { Patient } \\
\left.\text { (Year of } d x^{a}\right)\end{array}$ & $\begin{array}{l}\text { Type of presentation } \\
\text { (Age onset/Age } \mathrm{dx} \text { ) }\end{array}$ & $\begin{array}{l}\% \mathrm{PCC}^{\mathrm{b}} \\
\text { activity }\end{array}$ & Genotype & Outcome \\
\hline$\overline{B L T}(1986)$ & Early (3d/23d) & 0.8 & ins/del, ins/del & Died 27d \\
\hline ALT (1989) & Early $(/ 1 d)$ & 1.9 & ins/del, ins/del & $\begin{array}{l}\text { Alive 10y. Moderate psychomotor delay. Muscular hypotonia. } \\
\text { Myocardiopathy. Weight p90th and height p50th LPD }{ }^{c} C^{d}\end{array}$ \\
\hline CBV (1995) & Early $(2 d / 10 d)$ & 2.2 & ins/del, ins/del & $\begin{array}{l}\text { Alive 4y. Severe psychomotor delay. Severe hypotonia. } \\
\text { S. West. Weight p50th and height p75th Gastrostomy. LPD.C }\end{array}$ \\
\hline MRA (1996) & Early $(7 d / 3 m)$ & 0 & ins/del, ins/del & $\begin{array}{l}\text { Alive 3y. Moderate psychomotor delay. Speech problems. } \\
\text { LPD.C }\end{array}$ \\
\hline PRG (1997) & Early $(19 d / 21 d)$ & 1.7 & E168K, E168K & $\begin{array}{l}\text { Alive } 2 y . \text { Normal development. Brunet-Lezine test: } 24 \mathrm{~m} \text {. } \\
\text { Weight and height p3th. LPD.C }\end{array}$ \\
\hline APJ (1994) & Early $(3 d / 1 m)$ & 1.2 & 1170insT, 1170insT & $\begin{array}{l}\text { Alive } 4.5 y . \text { Moderate psychomotor delay. Muscular } \\
\text { hypotonia. MRI ( } 2 y) \text { : mild frontal atrophy. Weight p75th and } \\
\text { height p90th. Gastrostomy. LPD.C }\end{array}$ \\
\hline SSL (1993) & Early $(5 d / 23 d)$ & 1.6 & 1170insT, 1170insT & Died $4 \mathrm{~m}$ when gastroenteritis with SSS \\
\hline SVL (1986) & Early $(2 d / 4 d)$ & 1.3 & A497V, A497V & $\begin{array}{l}\text { Alive 13y. Normal development. Muscular weakness. Normal } \\
\text { MRI (9y). Gastrostomy. Weight p50th and height p10th. } \\
\text { LPD.C }\end{array}$ \\
\hline
\end{tabular}

ins/del is 1218del14ins12 mutation.

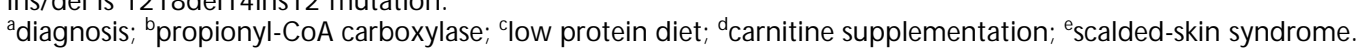


Table 5 Genotype and clinical outcome of 19 heterozygous PCCB-deficient patients

\begin{tabular}{|c|c|c|c|c|}
\hline $\begin{array}{l}\text { Patient } \\
\left.\text { (Year of } d x^{a}\right)\end{array}$ & $\begin{array}{l}\text { Type of presentation } \\
\text { (Apge onset/Age dx) }\end{array}$ & $\begin{array}{l}\% \mathrm{PCC}^{\mathrm{b}} \\
\text { activity }\end{array}$ & Genotype & Outcome \\
\hline AJA (1990) & Early (10d/10d) & 0 & ins/del, R44P & $\begin{array}{l}\text { Alive 9.5y. IQ } \text { : 70. Hypotonia. Partial epilepsia. Weight } \\
\text { p75th and height p25th LD }{ }^{d} C^{e}\end{array}$ \\
\hline PVD (1991) & Early (20d/1m) & 2.3 & ins/del, G131R & Died $1.5 \mathrm{~m}$ \\
\hline VMP (1989) & Early $(4 d / 14 d)$ & 5 & ins/del, A497V & $\begin{array}{l}\text { Alive 10y. Moderate mental retardation. MR: discrete } \\
\text { cortical atrophy. Weight p50th and height p25th. } \\
\text { LPD.C.Ileu }\end{array}$ \\
\hline EAC (1995) & Early $(20 d / 2 m)$ & 5 & ins/del, R512C & Died 3y after febrile illness with diarrhoea \\
\hline AG (1988) & Early $(3 d / 7 d)$ & 0 & ins/del, W531X & Died $15 \mathrm{~d}$. Congenital cardiopathy and hypothermia \\
\hline NPU (1989) & Early $(6 \mathrm{~d} / 5 \mathrm{~m})$ & 3 & ins/del, E168K & $\begin{array}{l}\text { Alive 9.5y. Mild psychomotor delay. Tremor } \\
\text { Myocardiopathy. LPD.C }\end{array}$ \\
\hline MBG (1983) & Early (4d/6d) & 0 & E168K, IVS1+3G->C & $\begin{array}{l}\text { Alive 15.5y. Moderate psychomotor delay. Muscular } \\
\text { hypotonia. MRI: mild cortico-subcortical atrophy. } \\
\text { Retarded puberal development. Weight p50th and } \\
\text { height p10th. LPD.C.Ileu }\end{array}$ \\
\hline DMS (1982) & Early $(15 \mathrm{~d} / 2 \mathrm{~m})$ & 1 & E168K, 1170insT & Lost to follow up at $2 y$ \\
\hline JRC (1997) & Early $(2 d / 5 d)$ & 1 & 1170insT, M442T & $\begin{array}{l}\text { Alive } 1.5 y \text {. Normal psychomotor development. Weight } \\
\text { p75th and height p50th. LPD.C }\end{array}$ \\
\hline PHG (1996) & Early (3d/15d) & 0 & 1170insT, L519P & $\begin{array}{l}\text { Alive } 2.5 y . \text { Normal psychomotor development. } \\
\text { Hypotonia. Weight and height p50th. LPD.C }\end{array}$ \\
\hline LVA (1981) & Early (2d/10d) & 0.6 & 1170insT, NDg & Died $2.5 y$ after measles with SSS ${ }^{h}$ \\
\hline DVA (1994) & Early (/1d) & $\mathrm{O}^{\mathrm{L}}$ & 1170insT, ND & Died 19d with SSS \\
\hline CJF (1991) & Early $(15 \mathrm{~d} / 2.5 \mathrm{~m})$ & $1.2^{\mathrm{L}}$ & A497V, S106R & Died $4 \mathrm{~m}$ with severe malnutrition and mycoardiopathy \\
\hline JGG (1974) & Late $(4 \mathrm{~m} / 16 \mathrm{~m})$ & 1.5 & ins/del, E168K & Alive 25y. Severely retarded. Myocardiopathy. LPD.C \\
\hline RSC (1989) & Late $(5 \mathrm{~m} / 6 \mathrm{~m})$ & 0 & ins/del, E168K & Died 16m \\
\hline LGA (1991) & Late $(2 \mathrm{~m} / 8 \mathrm{~m})$ & 1.2 & ins/del, E168K & $\begin{array}{l}\text { Alive 8y. Psychomotor delay. Autism. Normal MRI (6y). } \\
\text { LPD.C.Ileu }\end{array}$ \\
\hline BJWG (1998) & Late $(4 \mathrm{~m} / 22 \mathrm{~m})$ & 1.1 & E168K, 1170insT & $\begin{array}{l}\text { Alive 2.5y. Mild psychomotor delay. Speech problems. } \\
\text { Partial epilepsia. MRI (1y): arachnoid cyst in left temporal } \\
\text { fossa. Weight p50th and height p97th. LPD.C }\end{array}$ \\
\hline AML (1997) & Late $(2 \mathrm{~m} / 7 \mathrm{~m})$ & 2.4 & E168K, 790-791insG+L17M & $\begin{array}{l}\text { Alive 2y. Psychomotor delay. Hypotonia. Dystonic } \\
\text { movements. Weight and height p3th. LPD.C.Ileu }\end{array}$ \\
\hline OVE (1996) & Late (5.5y/5.5y) & 11 & IVS10-11del6, R410W & $\begin{array}{l}\text { Died 5.5y after a metabolic stroke. Basal ganglia } \\
\text { infarction }\end{array}$ \\
\hline
\end{tabular}

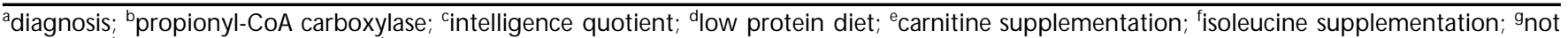

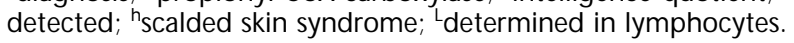

\section{Northern blot analysis}

Northern blot analysis of total fibroblasts RNA was performed on six PCCA-deficient patients, all showing normal amounts of both $\alpha-P C C$ and $\beta$-PCC mRNA as previously reported. ${ }^{23}$ In PCCB-deficient patients, we analysed the genetic compounds which showed no $\beta$-subunit by western blot, detecting no $\beta$-PCC mRNA in homozygous patients for ins/del or 1170insT mutations (Figure2, lanes1, 2) and normal in size and amount in those compound heterozygotes for ins/del and R512C or 1170insT and L519P mutations (Figure2, lanes3, 4). $\beta$ chain mRNA in patients carrying E168K in homozygous fashion and those heterozygous for ins/del and G131R or ins/ del and W531X was also normal (Figure2, lanes5-7).

\section{Discussion}

The aim of the present study was to investigate whether the different genotypes found in Spanish PA patients could be correlated to the clinical phenotypes of the disease.

To classify patients having defective PCCA or PCCB genes our first method was the measurement of PCC activity in

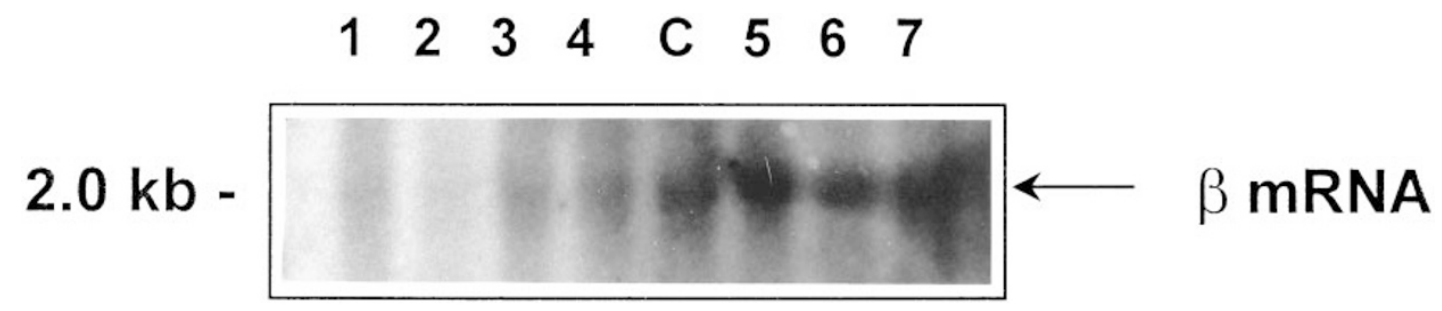

Figure 2 Northern blot analysis of $20 \mu \mathrm{g}$ of total fibroblasts RNA from PCCB-deficient patients. C, control cell line. Lanes 1-4: patients MRA, APJ, PHG and EAC; lanes5-7: patients PRG, PVD and AG, respectively. 
parents, since the excess synthesis of $\beta$-subunit over $\alpha$-subunit ${ }^{27}$ allows a full measure of PCC activity in most parents of patients with $\beta$-subunit defects. In our study, the identification of the defective gene based on this approach correlated well with those obtained by ${ }^{3} \mathrm{H}$-biotin labelling experiments and by complementation tests. In the five parents of PCCBdeficient patients with discrepant results, the intermediate PCC activity found could be explained by taking into account the interindividual variation in PCC activity which showed a normal wide range in both fibroblasts and lymphocytes, or as a result of the presence of stable dysfunctional $\beta$-subunits which could result in a lower PCC activity value. This could be the explanation for the data obtained in parents PRG and NPU bearing the E168K mutation.

\section{Genotype-phenotype correlation}

On the whole, propionic acidaemia is a very severe disease as illustrated by the number of deaths (15/37) and the number of retarded living patients (15/21); only six patients are developing normally. There is no correlation between clinical phenotype and the affected gene, since the proportion of deaths (44\% in PCCA-deficient and 39\% in PCCB-deficient patients) or retardations (33\% in PCCA-deficient and $42 \%$ in PCCB-deficient patients) is similar in both molecular groups.

Our series of PCCA-deficient patients is characterised by the fact that each patient had a unique genotypic combination. Most patients showed a total absence of $\alpha$ and $\beta$-PCC subunits because the latter is intrinsically unstable and rapidly degrades if not complexed with $\alpha$-subunit. ${ }^{27}$ Detectable amounts of $\alpha$ and $\beta$ subunits were only found in fibroblasts of patient SAG, a compound heterozygote for R52W and 1771IVS-2del9 mutations, the latter causing an in-frame deletion of 18 amino acids from the protein sequence. ${ }^{23}$ Either allele could account for the residual traces of $\alpha$ and $\beta$-PCC subunits which could be related to the normal development of the patient who has always tolerated a regular protein diet. In addition, patient $\mathrm{MSH}$, homozygous for the splicing mutation 1824IVS + 3de14 which cause the same in-frame deletion, also exhibits a relatively mild and long surviving course of the disease. The presumed severity of the nonsense mutations R288X and S537X, which would result in truncated proteins lacking functionally important domains, correlates well with the early presentation and severe phenotype of the patients carrying them. However, the functional consequences of the missense mutations A113T, I139T, and G606R cannot be clearly predicted without expression studies. The presence of the A113T and I139T changes were found to relate to a milder expression of the disease in patients JMMO and ESG. However, the homozygous patient for the G606R mutation also carrying the I450V polymorphism, presented neonatally and proved to be fatal. The polymorphic variation I450V is over-represented in PCCA-deficient patients, $16 \%$ versus $9 \%$ in controls, ${ }^{24}$ and may contribute with different susceptibility to disease as has been described for the variant 625G->A and 511 C->T alleles in ethylmalonic aciduria. ${ }^{28}$

Concerning the mutations found in PCCB-deficient patients, we have identified three (1170inst, ins/del and 790-791insG) which could be categorised as null mutations as they produce a premature stop codon. The two mRNAminus mutations 1170 inst and ins/del, resulting in nondetectable $\beta$-PCC subunit, are clearly related to a severe phenotype, since all homozygous patients for these mutations presented neonatally, and the four still alive are hypotonic and mentally retarded despite excellent compliance with therapy. Phenotype correlation with the mutations affecting splice site of exon 1 (IVS1 + 3G - >C) and 11 (IVS10-11 del6) is difficult to ascertain because they are present only on one chromosome. However, it is worth noting the high residual PCC activity and the unusual manifestation of the disease in the compound heterozygote (OVE) with the R410W and IVS10-11del6 mutations, ${ }^{17}$ the latter causing the loss of exon 11 that generates an in-frame transcript and therefore possibly would produce a partially functional protein. Among the 11 missense mutations identified, E168K which results in detectable $\beta$-PCC protein is currently the second most frequent in Spain. It has been detected in one homozygous and in 8 compound heterozygous patients, all of them functionally hemizygotes, as E168K is combined with a null mutation on the other allele. The presence of the E168K mutation seems to confer a less severe PA phenotype since five of these nine patients presented a late-onset form of the disease and seven of them are alive with variable developmental delay. The A497V mutation has been detected in three patients from a small village in central Spain. This fact may be explained by consanguinity-CJF and VMP are distally related- or by other factors such as genetic drift. The patient who is a homozygous carrier presents with excellent clinical evolution. Finally, we have identified three changes in exon 15 (R512C, L519P and W531X), which has been postulated to be a hot spot for mutations. ${ }^{20}$ The results of a recent study using the in vivo mammalian two-hybrid system in COS cells show that these three mutations remove the ability to form $\beta-\beta$ homodimers, ${ }^{29}$ suggesting that the $\beta$-PCC carboxyl terminus could be part of a functional domain involved in homomeric association, and therefore mutations in this region would severely affect PCC enzyme, explaining the severity of the disease in patients carrying R512C and W531X mutations in combination with ins/del.

In summary, several conclusions can be drawn from the present study.

(1) Wehave identified most of the putative disease-causing mutations in our PA population which will allow an accurate and rapid prenatal diagnosis and carrier status detection for family members-the only reliable way to determine carriers of PCCB mutations. ${ }^{18}$ 
(2) In relation to the affected gene, a poor prognosis of the disease could be expected for the previously described PCCA-deficient patients who carried mutations that affect mRNA stability. ${ }^{27,30}$ However, near half our PCCA-deficient patients presented with a mild phenotypic expression, probably as a result of the presence of normal amounts of $\alpha$-subunit mRNA, ${ }^{24}$ indicating a different effect of the mutations.

(3) We have found good correlation with certain mutations which can be considered as null with a severe phenotype, while other missense mutations tend to be related to the late and mild form of the disease.

Future expression studies will provide more insight into the effect of each mutation on the PCC enzyme and its possible relationship with the patient's phenotype. In any case, we believe that irrespective of the PA genotype, interindividual variations in enzymes involved in the secondary pathways which would prevent propionic acid and its toxic derivatives from accumulating, could be of importance in the phenotypic expression of the disease. This is in accordance with the now generally accepted idea of complexity in monogenic traits. ${ }^{31}$

\section{Acknowledgements}

The authors thank the patients, their parents and the following physicians: Dr F Gayoso (Sevilla), Dr JM Fraga and Dr ML Couce (Santiago de Compostela), Dr A Fernández (Murcia), Dr M Tomás, Dr ML Cabello and Dr AM García (Valencia), Dr M Martí, Dr JC Cabrera and $\operatorname{Dr} L$ Peña (Las Palmas de Gran Canarias), Dr E Yoldi (Pamplona). Dr E Pérez Ruiz (San Sebastián), Dr J Figueras and Dr J M oreno (Barcelona), Dr M M olina (Bilbao), Dr C Galiana and Dr Del Valle (Palma de Mallorca) for their hel pful cooperation. We also thank C Hernández, A Sánchez and I Reina for their excellent technical assistance. This work was supported in part by grants from Fundación Ramón Areces, and the Fondo de Investigaciones Sanitarias (95/0477), (98/0185). The institutional grant of 'Fundación Ramón Areces' to the Centro de Biología Molecular 'Severo Ochoa' is gratefully acknowledged.

\section{References}

1 Fenton WA, Rosenberg LE: In: Scriver CR, Beaudet AL, Sly WS, ValleD (eds). The M etabolic and M olecular Bases of Inherited Disease. McGraw-Hill: New York, 1995, vol 1, pp 1423-1449.

2 Gravel RA, Lam KF, Mahuran D, Kronis A: Purification of human liver propionyl-CoA carboxylase by carbon tetrachloride extraction and monomeric avidin affinity chromatography. Arch Biochem Biophys 1980; 201: 669-673.

3 Lamhonwah AM, Lam KF, Tsui F, Robinson B, Saunders ME, Gravel RA: Assignment of the $\alpha$ and $\beta$ chains of human propionylCoA carboxylase to genetic complementation groups. Am J Hum Genet 1983; 35: 889-899.

4 Gravel RA, Lam KF, Scully KJ, Hsia YE: Genetic complementation of propionyl-CoA carboxylase deficiency in cultured human fibroblasts. Am J Hum Genet 1977; 29: 378-388.

5 Lamhonwah AM, Barakiewicz TJ, Willard HF, Mahuran DJ, Quan F, Gravel RA: Isolation of CDNA clones coding for the $\alpha$ and $\beta$ chains of human propionyl COA carboxylase: Chromosomal assignments and DNA polymorphism associated with PCCA and PCCB genes. Proc Natl Acad Sci USA 1986; 83: 4864-4868.
6 Kraus JP, Williamson CL, Firgaira FA et al: Cloning and screening with nanogram amounts of immunopurified mRNAs: CDNA cloning and chromosomal mapping of cystathionine $\beta$-synthase and the $\beta$ subunit of propionyl-CoA carboxylase. Proc Natl Acad Sci USA 1986; 83: 2047-2051.

7 Wolf B, Rosenberg LE: Heterozygote expression in propionyl coenzyme A carboxylase deficiency. Differences between mayor complementation groups. J Clin Invest 1978; 62: 931-936.

8 Ugarte M, Pérez-Cerdá C, Rodríguez-Pombo P et al: An overview of mutations in the PCCA and the PCCB genes causing propionic acidaemia. Hum Mutat 1999; 14: 275-282.

9 Wolf B, Hsia YE, Sweetman L, Gravel RA, Harris DJ, Nyhan WL: Propionic acidaemia: a clinical update. J Pediatr 1980; 99: 835-846.

10 Surtees RAH, Matthews EE, Leonard JV: Neurologic outcome of propionic acidaemia. Pediatr Neurol 1992; 8: 333-337.

11 Lehnert W, Sperl W, Suormala T, Baumgartner ER: Propionic acidaemia: clinical, biochemical and therapeutic aspects. Experience in 30 patients. Eur J Pediatr 1994; 153: S68-S80.

12 Van der Meer SB, Poggi F, Spada M, Bonnefont JP et al: Clinical outcome and long-term management of 17 patients with propionic acidaemia. Eur J Pediatr 1996; 155: 205-210.

13 Costil J, Debard A, Guilhaume A, Charpentier C, Pousset J, Brissaud HE: Acidimie propionique. A propos de deux observations. Ann Pediat 1979; 26: 283-288.

14 Merinero B, Del Valle JA, Jímenez A et al: Late onset type of propionic acidaemia: case report and biochemical studies. J Inher Metab Dis 1981; 4: 71-72.

15 Del Valle JA, Merinero B, García MJ, Ugarte M, Omeñaca F, Neustadt G: Leukocyte propionyl-CoA carboxylase deficiency in a patient with ketotic hyperglycinemia. J Inher Metab Dis 1981; 3: 93-94.

16 Figueras J, Ribes A, Vilaseca MA et al: Forma neonatal de acidemia propiónica. An Esp Pediatr 1988; 29: 459-462.

17 Pérez-Cerdá $C$, Merinero $B$, Martí $M$ et al: An unusual late-onset case of propionic acidaemia: biochemical investigations, neuroradiological findings and mutational analysis. Eur J Pediatr 1998; 157: $50-52$

18 Muro S, Pérez-Cerdá C, Rodríguez-Pombo $\mathrm{P}$ et al: Feasibility of DNA-based methods for prenatal diagnosis and carrier detection of propionic acidaemia. J Med Genet 1999; 36: 412-414.

19 Suormala T, Wick H, Bonjour JP, Baumgartner ER: Rapid differential diagnosis of carboxylase deficiencies and evaluation for biotin-responsiveness in a single blood sample. Clin Chim Acta 1985; 145: 151-162.

20 Rodríguez-Pombo P, Hoenicka J, Muro S et al: Human propionylCoA carboxylase $\beta$ subunit gene: exon-intron definition and mutational spectrum in Spanish and Latin American propionic acidaemia patients. Am J Hum Genet 1998; 63: 360-369.

21 Old J: Fetal DNA analysis. In: Davies K (ed.). Human Genetic Diseases: a Practical Approach. IRL Press: New York, 1986, pp 1-16.

22 Chomczynski P, Sacchi N: Single-step method of RNA isolation by acid guanidinium thiocyanate-phenol-chloroform extraction. Anal Biochem 1987; 162: 156-159.

23 Richard E, Desviat LR, Pérez B, Pérez-Cerdá C, Ugarte M: Genetic heterogeneity in propionic acidaemia patients with $\alpha$-subunit defects. Identification of five novel mutations, one of them causing inestability of the protein. Biochim Biophys Acta 1999; 1453: 351-358.

24 Richard E, Desviat LR, Pérez B, Pérez-Cerdá C, Ugarte M: Three novel splice mutations in the PCCA gene causing identical exon skipping in propionic acidaemia. Hum Genet 1997; 101: 93-96.

25 Muro S, Rodríguez-Pombo $P$, Pérez $B$ et al: Identification of four novel mutations in the PCCB gene in European propionic acidaemia patients. Hum Mutat 1999; 14: 89-253 (on line).

26 Rodríguez-Pombo P, Hoenicka J, Muro S et al: Human propionylCoA carboxylase $\beta$ subunit gene: exon-intron definition and mutational spectrum in Spanish and Latin American propionic acidaemia patients. Errata. Am J Hum Genet 1999; 65: 276. 
27 Ohura T, Kraus P, Rosenberg LE: Unequal and differential degradation of propionyl-CoA carboxylase subunits in cells from normal and propionic acidaemia patients. Am J Hum Genet 1989; 45: 33-40.

28 Gregersen N, Winter VS, Corydon MJ et al: Identification of four new mutations in the short-chain acyl-COA dehydrogenase (SCAD) gene in two patients: one of the variant alleles, 511 C- > T, is present in an unexpectedly high frequency in the general population, as was the case for $625 \mathrm{G}->\mathrm{A}$, together conferring susceptibility to ethylmalonic aciduria. Hum Mol Genet 1998; 7: 619-627.
29 Muro S, Pérez B, Rodríguez-Pombo P, Desviat LR, Pérez-Cerdá C, Ugarte $M$ : Identification of mutations affecting the $\beta-\beta$ homomeric interaction in propionic acidaemia: an approach towards the determination of $\beta$-PCC functional domains. J Inher M etab Dis 1999; 22 (suppl 1): 90.

30 Lamhonwah AM, Gravel RA: Propionic acidaemia: absence of alpha-chain mRNA in fibroblasts from patients of the pccA complementation group. Am J Hum Genet 1987; 41: 1124-1131.

31 Scriver ChR, Waters PJ: Monogenetic traits are not simple. Lessons from phenylketonuria. TIG 1999; 15: 267-272. 